\title{
The moderating effect of social capital on co-regulated learning for MOOC achievement
}

\author{
Rawad Chaker $^{1}$ (1) $\cdot$ Maria Antonietta Impedovo ${ }^{2}$ (I)
}

Received: 5 May 2020 / Accepted: 27 July 2020 / Published online: 5 August 2020

(C) Springer Science+Business Media, LLC, part of Springer Nature 2020

\begin{abstract}
The aim of this paper is to track down elements of self-regulated learning in a massive open online course regarding social capital. Specifically, the study is oriented to explore the relationship between feeling of belonging to an online community and individual and collective regulation of learning. For this aim, a combination of two already tested scales was operated, adapted for the research interests of this study and administered to a sample of MOOC participants. Several structural equation modelling analyses demonstrate that co- and self-regulated learning strategies lead to MOOC achievement (final exam score), and social capital is only a moderator of co-regulated learning (collective evaluation of content and collective decision-making) but not for selfregulated learning (individual environment control).
\end{abstract}

Keywords Co- and self-regulated learning $\cdot$ Online learning $\cdot \mathrm{MOOC} \cdot \mathrm{Community}$ of practice $\cdot$ Social capital

\section{Introduction}

Massive Open Online Courses (MOOCs) share the common implicit expectation that learners are expected to be autonomous and manage their own learning (Tschofen and Mackness 2012, p. 126). Indeed, students are increasingly confronted with the need to learn "alone" with the computer or mobile learning devices, to take advantage of online and open courses.

Rawad Chaker

rawad.chaker@univ-lyon2.fr

Maria Antonietta Impedovo

maria-antonietta.impedovo@univ-amu.fr

1 Lyon 2 University, 86 rue Pasteur, 69007 Lyon, France

2 Aix-Marseille University, 52 avenue Escadrille Normandie - Niemen, 13013 Marseille, France 
For this reason, self-regulated learning (SRL) has increasingly received attention in educational literature as a crucial factor related to learner's behavior in MOOCs (Lee et al. 2019). SRL is considered as a transversal competence of "learning to learn" (Schunk and Zimmerman 1998). Despite arguments about the importance of selfregulated learning in MOOCs, understanding of the topic is limited (Lee et al. 2019; Terras and Ramsay 2015). Our research design takes interest in the role of communicating with others in learning success, as MOOCs often integrate in their instructional design the possibility to interact with peers and share experience within the discussion spaces. As SRL and social interactions being both linked in the literature to MOOCs achievement, we aim to study the relationship between SRL and social interactions and the part of their participation to learning success. In other words, we aim to investigate the causal process involving SRL, social interactions, and learning in a MOOC context. Indeed, many studies about the influence of social factors on SRL take into consideration the rich research highlighting the social influence on motivation and learning (for i.e., Jones et al. 2008). In our case, we study the causal relationships of SRL as a psycho-sociological construct, sense of belonging to an online learning community and learning achievement. Our main research question (RQ) is: do learning regulation and social capital both participate in comparable proportions to learning, or is there a more complex underlying model needs to be exposed? In other words, our main RQ investigates the causal process involving regulated learning, social relations and learning in a MOOC context. Proposing a contribution in this direction, this paper will measure individual and collective regulation of learning among participants in a project management MOOC. These variables will be put in relation with social capital and the final exam score of the course.

In the following section, a recent discussion of literature about SRL and MOOCs is briefly presented, followed by a study based on a combination of two instruments measuring learning regulation and social capital.

\section{Theoretical framework}

\subsection{Exploring SRL for online learning: Models and methodological challenges}

SRL is widely debated in the literature (e.g., Artino 2007) and considered as a factor affecting students' success in traditional online learning environments (Cho and Shen 2013). Self-regulation involves cognitive, affective, motivational and behavioral components that provide the individual with the capacity to adjust their actions and goals to achieve the desired results in light of changing environmental conditions (Boekaerts et al. 2000). In this perspective, it is understood as a "cross competence" that helps the individual in the management of their own learning (Graham et al. 1992), reacting and interacting with the environment, in a mutual adaptation.

Several models analyze SRL, as for example the social-cognitive theory (Bandura 1989). The socio-cognitive model of SRL developed by Zimmerman (2001) is widely considered in literature. He identified the learning process in: 1) Metacognition, indicating reflection on the cognitive activity which is expressed in constant analysis and evaluation of its course; 2) Motivation, as awareness of its objectives, analyzing the causes of learning success or failure and focusing its energies towards the final goal; 3 ) 
Behavioral, exercising choices and controlling them during the activity. Winne and Hadwin (2008) attribute more importance to metacognitive factors and cognitive strategies aimed at adapting to the task. Borkowski (1992) also puts out how cognitive, motivational, personal and situational skills underly the ability of knowledge and cognitive meta-control. SRL plays a central role in achieving optimum levels of learning according to Pintrich (2000). In his model, Pintrich (2000) recognizes four stages in the self-regulating process, not linearly ordered: anticipation, planning and activation; monitoring; control; reaction and reflection. Azevedo (2008) considers that the various main stages of SRL (planning, monitoring, control and reflection) are not regular, also considering aspects as permanent aspects vs transient aspects, the role of the contextual elements in supporting processes of self-regulation, the number and types of processes involved.

Different studies were conducted to explore SRL in online higher education. A systematic review of Broadbent and Poon (2015) selects time management, metacognition, effort regulation and critical thinking as positive correlates with academic achievement in online education. Recent learning methods (Hakkarainen et al. 2002) offer opportunities for students to engage in SRL paths, encouraging students to set their own goals, emphasizing collaboration and new forms of scaffolding during learning, creating more challenging situations.

Other attempts have been made to take into consideration, within the learning regulation framework, collective strategies. Social aspects of learning regulation comprise contrasting self-regulated learning, co-regulated learning (CoRL) and socially shared regulation of learning (SSRL) (Hadwin et al. 2011). Hadwin et al. (2011) define CoRL as the "temporary coordination of self-regulation amongst self and others". CoRL can be mobilized for individual and/or collective tasks, whereas SSRL is mobilized whenever convergent tasks are needed in the service of a co-constructed or shared outcome/product (Hadwin et al. 2011. In our context, as: 1) MOOC learning communities are "short-term" communities of practice (De Waard et al. 2011); 2) MOOC participants engage in solo learning process but can share learning regulation methods and technique; we decided to consider in our study SRL and CoRL. Our paper will particularly focus on CoRL.

Considering commonalities and differences between traditional online courses and MOOCs, there is need for more empirical investigation of SRL in MOOCs, becoming one of the five main topics for future MOOC research (Gasevic et al. 2014), as discussed in the next section.

\subsection{Self- and co-regulation in MOOC learning}

The study of Lee et al. (2019) showed that research on SRL in MOOCs has grown increasingly, confirming that SRL positively affected MOOC learning.

About the sense of academic achievement, Magen-Nagar and Cohen's (2016) show that learning strategy was a significant mediator for motivation in a MOOC for highschool students. Similarly, Kizilcec et al. (2017) found that goal setting and strategic planning were significant positive predictors of learners' goal achievement. About motivational regulation strategies, Littlejohn et al. (2016) revealed that high selfefficacy scores specifically relate to previous exposure to MOOC content. This result is explained by the familiarity with the MOOC model. 
Some solutions are discussed in the literature to promote SRL in MOOC learning, like developing a prototype widget that allows MOOC learners to compare their behaviors with successful MOOC learners' behaviors (Davis et al. 2016; face-to-face MOOC study group (Chen and Chen 2015); study planning module with prompts (Davis et al. 2016.

Based on these previous studies, we seek to verify if, in our context, learning can be predicted by self- and co-regulated learning constructs:

\section{- H1: Learning regulation predicts learning in a MOOC context}

Considering these studies, we notice that a few of them proposed to investigate the relationships between learning strategies and social relations in MOOCs. For instance, Young and Fry (2008) highlighted the significant effect of the learning environment on SRL but did not include social relations or interactions within his learning environment model. As stated by Liu (2012), many studies (Boekaerts et al. 2000; Schunk and Zimmerman 1998) propose that self-regulated learners could efficiently control their own learning activities by monitoring their own thinking processes and seeking help. Nevertheless, in their study among pre-service teachers, Liu (2012) did not find any significant results supporting SRL as a significant outcome of social support from classmates. The longitudinal study conducted by Perry et al. (2018) among a diverse sample of urban youth suggests that peer support predicts SRL relatively well. Peers constitute "salient sources" for SRL: it was also found by Jones et al. (2008) to be related with SRL strategies. In their model, SRL is seen as an outcome of social capital. To further explore the relationship between self- and co-regulated learning and social interaction, we will focus in the following sections on the concepts of social capital and sense of belonging in a MOOC community. As few studies analyze the role of CoRL in MOOC achievement, or the relationships between CoRL and social capital in a learning environment, our contribution aims to fill that gap.

\subsection{Social capital, feeling of belonging and learning achievement}

The first MOOC was designed as a connectivist MOOC (cMOOC) (Siemens et al. 2010). Connectivism explains learning as a process enabled through connections and that "nurturing and maintaining connections is needed to facilitate continual learning" (Siemens 2005). Connectivism is a theory that emphasizes the role of sociocultural context and community building for learning. cMOOC learning environments, then, often afford community building and social networking through discussion spaces and social media, such as Facebook or Twitter. xMOOCs tend to focus on content delivery (e.g., lectures and materials), and thus downplay technologies that enhance social experiences, although often including basic discussion forums to support peer-to-peer interaction (Johnson 2013.

As such, many studies link social interaction to learning through the connectivist theory (as examples, see Milligan et al. 2013 and Bozkurt and Keefer 2018). Social capital is the relationships among participants of a social network and how these are used to gain benefits (Adler and Kwon 2002; Coleman 1990). We use social capital as a multifaceted construct that encompasses the complexity of human interactions and "others" as a mobilizable resource for goal attainment. 
A MOOC can be considered as a "short-term" community of practice. All the participants are brought together to share community, domain knowledge and practice for a short period of time (De Waard et al. 2011). Wenger et al. (2002) define communities of practice as: "groups of people who share a concern, a set of problems, or a passion about a topic, and who deepen their knowledge and expertise by interacting on an ongoing basis". A definition of online learning community of practice relates to identity sharing, experience and tacit knowledge (Oztok et al. 2015) like professional knowledge and expertise (Hughes and Kritsonis 2007. For Oztok et al. (2015), social capital is part of the resources inherent in an online learning community available and accessible to others. Different studies use the model of community of practice for MOOC exploration. Indeed, social relationships among peers can constitute virtual communities of practice, as proposed by many studies (i.e. Kellogg et al. 2014; Sarirete and Brahimi 2014; Gillani and Eynon 2014, specifically in the case of professional development MOOCs (i.e. Jones et al. 2016; Chae et al. 2018; Struminger et al. 2017). Jones et al. (2016) show how fostering communities of learners to develop in MOOCs encourages students to work cooperatively, considering alternative perspectives.

The importance of peer interaction and social support for learning is widely discussed. The specific features of the MOOC challenge the establishing of online interpersonal interactions. Traditional social support research focuses on communicative action that leads to effective comfort, information, knowledge, and material exchange. In the social capital theory, Bourdieu defines social capital as "the aggregate of the actual or potential resources which are linked to possession of a durable network of more or less institutionalized relationships of mutual acquaintance and recognition" (Bourdieu 1986). Specifically, the belonging support is the type of support that nurtures the sense of social belonging. Recent studies applying social support to online communication showed that the informational and emotional support were the most requested supports in online social networks (Lin et al. 2012. According to Hsu et al. (2018) the belonging support became easy to access and observed in the online environment.

Based on this theoretical framework and previous empirical results, we seek to investigate social capital causality order within the MOOC achievement as self- and colearning regulation outcome model. Intermediate effects are complex, such as mediating effects and moderating effects (Baron and Kenny 1986). We will verify the following hypotheses:

- H2: Social capital is a co-variable of learning regulation for MOOC learning

- H3: Social capital mediates between learning regulation and MOOC learning

- H4: Social capital moderates learning regulation for MOOC learning

As we will use Kaplan et al.'s (2017) learning regulation measuring tool, which comprises CoRL strategy constructs, we added another research question investigating to which kind of regulation strategy, collective or individual, social capital relates to. Hence, the fifth hypothesis:

- H5: Social capital specifically relates to co-regulation strategies, with MOOC learning as an outcome 
We employed in this work structural equation modelling (SEM) to verify our hypotheses.

\section{Method}

\subsection{Sample and data collection}

We conducted our study within the population of the Project Management MOOC 13th edition (from September to November 2018), delivered by a public university in France (Ecole Centrale of Lille). The course lasts six weeks with a paid certification track. A questionnaire (a Google Form link, about $10 \mathrm{~min}$ to complete) was posted on the MOOC platform at the fourth week of the course and was kept available until the end of the sixth week. Among the 20,815 registrants enrolled in the MOOC, 3326 were active at the beginning of the course (16\%) (they completed at least one assignment). By the end of the 6th week, $N=454$ completed the questionnaire (13.65\% of active participants; $55.66 \%$ Females). As they are all active participants, our sample could constitute a bias for our study. Hence, we must consider this fact for our results.

We chose the Project Management (PM) MOOC to conduct our study, as it relies, in its instructional design, on the relationship between peers to advance in the course. It is strongly advised to use the discussion spaces. Following each educational element, such as videos, quizzes or open questions, a discussion forum was introduced. The discussion forums are widely used by course participants. In addition, there are PM MOOC official accounts on social networks (Facebook and Twitter) which are used intensively as an extension of the MOOC platform (for discussion and deliverables posting). We posted the link to the questionnaire at week 4 as posting it at the beginning of the course would not give enough time for participants to hypothetically develop a sense of belonging to the online learning community.

\subsection{Ethics}

The researchers specified at the beginning of the questionnaire that the data collected from the study will only be used for a scientific purpose and will remain strictly confidential.

\subsection{Data analysis}

The statistical data analyses (descriptive statistics, variance analyses, factorial analyses and correlations) were made with IBM SPSS 23C. The structural equation modelling and confirmatory factorial analyses were made with Amos 23@.

\subsection{Measures}

\subsubsection{Self- and co-regulated learning}

Despite the maturity of the literature over the last two decades, it does not seem to have emerged a single standard for the measurement of SRL (Azevedo and Jacobson 2008). 
To study SRL, researchers have attempted to propose standardized instruments and assessments (for example, the MSQL of Pintrich et al. 1993). The ERICA scale (Kaplan et al. 2017) (Table 1) measures the regulation strategies' levels that learners use both individually and collectively. We selected this scale as it has a double advantage: it measures both self- and co-regulated learning, and it has been validated in French, since our study sample comes from the French speaking area. ERICA is oriented to understanding how learners regulate their learning in contemporary learning environments and comprises 30 items. We chose this instrument to verify if social capital would interact only with CoRL, SRL, both of them or neither of them.

For Kaplan (2014), learning regulation can be separated into four different phases: anticipation, monitoring, assessment and decision making. He set apart monitoring as an independent phase (which could be initiated throughout the meta-cognitive process), added collective decision making, as well as a collective dimension to the assessment phase, which could be related to Zimmerman's (1998) self-reflection phase. The phases are made of one or two micro-level regulation strategies.

Individual anticipation of materials and references (IAR) pertains to seeking standards against which one can decide what to learn and to which extent, as well as to measure one's attainments (Winne and Hadwin 2008, cited by Kaplan et al. 2017). Example of item: I select documents that will be of use for my learning (e.g. books, web pages, software.

Individual environmental control (IEC) "pertains to control a learner exerts on the environmental conditions that provide the comfort one feels one would like or even need in order to study" (Kaplan et al. 2017). Example of item: I choose the most appropriate locations for my learning.

Individual tracking and monitoring (ITM) "can be typified as any strategy enabling deliberate metacognition. By keeping track of one's learning activity (in an automated way such as with software generated logs, or by taking notes in a logbook or weblog), one is providing the means for oneself to reflect on one's processes and assess them" (Kaplan et al. 2017). Example of item: I take down notes on a notepad or in my diary about the state of my progress regarding my education.

Collective evaluation of content (CEC) is a strategy in which "learners readily seek to evaluate their progress by comparing attainments with peers and through discussion e.g., with alumni" (Kaplan et al. 2017). Example of item: I sometimes confer with other learners in order to situate my knowledge relative to what I still need to acquire.

Table 1 Learning regulation strategies measured with ERICA (Kaplan et al. 2017)

\begin{tabular}{lll}
\hline Phase & Code & Regulated strategy \\
\hline Anticipation & IAR & Individual anticipation of materials and references \\
& IEC & Individual environmental control \\
Monitoring & ITM & Individual tracking and monitoring \\
Assessment & CEC & Collective evaluation of content \\
& IEM & Individual evaluation of method \\
Decisions & CDM & Collective decisions for method change \\
\hline
\end{tabular}


Individual evaluation of method (IEM) "refers to thoughts the learner may have on the process being used to achieve desired learning" (Kaplan et al. 2017). Example of item: I sometimes question my learning method.

Finally, "decision-making marks the change that the agentic learner intends to make", and collective ones "venture to discern decisions that are made collectively" (Kaplan et al. 2017). Example of item: Changing methods used for learning is done following a decision made collectively.

The original subscales had an internal reliability between 0.75 and 0.89 . Items are coded on a Likert-type scale spanning $(0-4)$ in which Never is coded 0 and Always is coded 4.

\subsubsection{Social capital}

We adapted in French (see Appendix) the instrument proposed by Chiu et al. (2006) based on Social Cognitive Theory and the Social Capital Theory for investigating the motivations behind people's knowledge sharing in virtual communities (21 items). The authors constructed a scale by a combination of the social capital theorized subdimensions (Nahapiet and Ghoshal 1998: the structural dimension of social capital (social interaction and ties), the relational dimension (trust, norm of reciprocity and identification) and the cognitive dimension (shared language and vision). Composite reliabilities of the original subdimensions were between 0.82 and 0.93 .

Social Interaction Ties (SIT), the essential element of social capital's structural dimension, are channels for information and resource flows (Chiu et al. 2006. Authors cite Nahapiet and Ghoshal (1998) proposition that in Social Capital Theory, "network ties provide access to resources". The structural dimension of social capital relates to collaboration, coordination, and interaction between members of a group (Tantardini and Kroll 2015). It relates to the connection between individuals of a social group (Adler and Kwon 2002). Example of item: I spend a lot of time interacting with some members in the PM MOOC virtual community.

Relational social capital refers to the nature and characteristics of relationships (Jiang and Liu 2015), and to the level of trust and reciprocity between individuals within an organization (Nahapiet and Ghoshal 1998). Trust (TR) is one the subconstruct of social capital's relational dimension. Trust is considered by Nahapiet and Ghoshal (1998) a condition for cooperative interactions between individuals. It helps maintaining relationships (Blau 1964). Trust, according to Putnam (1993), "enables participants to act together more effectively to pursue shared objectives". Example of item: Members in the PM MOOC virtual community are truthful in dealing with one another.

Norm of reciprocity (NR) "refers to knowledge exchanges that are mutual and perceived by the parties as fair" (Chiu et al. 2006. The authors cite Blau (1964): "actions that are contingent on rewarding reactions from others and that cease when these expected reactions are not forthcoming." Example of item: I know that other members in PM MOOC virtual community will help me, so it's only fair to help other members.

Identification (ID) refers to "one's conception of self in terms of the defining features of self-inclusive social category" (Bagozzi and Dholakia 2002, cited by Chiu et al. 2006. Example of item: I feel a sense of belonging towards the PM MOOC virtual community. 
In the cognitive dimension of social capital, shared language (SL) addresses shared codes and language that "facilitate a common understanding of collective goals and the proper ways of acting in virtual communities" (Tsai and Ghoshal 1998, cited by Chiu et al. 2006. Example of item: Members in the PM MOOC virtual community use understandable communication pattern during the discussion.

Shared vision (SV) is viewed as "a bonding mechanism that helps different parts of an organization to integrate or to combine resources" (Tsai and Ghoshal 1998, cited by Chiu et al. 2006. According to Tantardini and Kroll (2015), "cognitive social capital refers to the capacity of the organization to share the same vision, mission and goals among members". Example of item: Members in the PM MOOC virtual community share the vision of helping others solve their learning problems.

The items are coded from 1 to 7 ( $1=$ I definitely don't agree; $7=$ I definitely agree). We asked two university English teachers to translate Chiu et al. (2006) social capital in online community measure scale into French and asked two other English teachers to translate it back into English. Then, the researchers confronted the results with the original scale, and discussed differences with the English teachers. The final result was obtained when everyone involved agreed to the final version of each item.

\subsubsection{Final exam score}

At the end of the course, participants must validate a final exam, with the passing threshold set at 70 out of 100 . The final exam score will be used as the MOOC achievement indicator (sometimes cited as MOOC learning ou MOOC achievement).

\section{Findings}

\subsection{Instruments validity}

The exploratory factorial analysis (EFA) for ERICA displayed many cross-loadings through different components (subscales). We used various measures of fit to find out to what extent our model explains the data: the chi-squared degrees of freedom ratio $\left(\chi^{2} / \mathrm{df}\right)$, the Comparative Fit Index (CFI), the root mean square error of approximation (RMSEA). Hu and Bentler (1999) consider that a value greater than 0.95 is preferable for the CFI and the NNFI, whereas for Bentler (1992) and Schumacker and Lomax (1996), a value greater than 0.90 is sufficient. Hu and Bentler (1999) also suggest that the RMSEA should be equal or lower than .06. The use of the GFI and AGFI indices is not recommended because they are significantly biased by non-normality and multicollinearity (Jöreskog et al. 1996). The confirmatory factorial analysis (CFA) (Table 2) for ERICA showed poor to average indices of fit of our sample: $\chi^{2} / \mathrm{df}=$ $2.11, p<0.001$; NNFI $=0.83 ; \mathrm{CFI}=0.85$; RMSEA $=0.075$. Hence, we corrected the model suppressing factor loadings beneath the 0.320 threshold and loadings across several latent factors. After correction, the EFA showed satisfactory items structure and reliability indices $(\alpha)$ of latent factors between 0.72 and 0.88 . CFA results displayed good fitness of our sample with the model: $\chi^{2 / d f}=1.46, p<0.001 ; \mathrm{NNFI}=0.95 ; \mathrm{CFI}=$ $0.96 ;$ RMSEA $=0.048$. 
Table 2 Confirmatory factorial analyses of ERICA and SK scales

\begin{tabular}{llllll}
\hline & $\chi^{2} / \mathrm{df}$ & $p$ & NNFI & CFI & RMSEA \\
\hline ERICA original model & 2.11 & 0.001 & 0.83 & 0.85 & 0.075 \\
ERICA corrected model & 1.46 & 0.001 & 0.95 & 0.96 & 0.048 \\
SK original model & 1.77 & 0.001 & 0.95 & 0.96 & 0.067 \\
SK corrected model & 1.60 & 0.118 & 0.98 & 0.99 & 0.05 \\
\hline
\end{tabular}

The same process was conducted for the social capital (SK) scale. The EFA displayed many cross-loadings through different subscales, so we corrected the model suppressing factor loadings beneath the 0.320 threshold and loadings across several latent factors. After correction, the EFA showed satisfactory items structure and reliability indices of latent factors between 0.75 and 0.89 . CFA results displayed excellent fitness of our sample with the model: $\chi^{2} / \mathrm{df}=1.60, p=0.118$; NNFI $=.98$; $\mathrm{CFI}=.99 ; \mathrm{RMSEA}=.05$.

\subsection{Instruments reliability}

Composite reliability (CR) was calculated for both instruments: for social capital, CR was between 0.75 and 0.91 for all subscales, and between 0.81 and 0.91 for ERICA subscales. This indicates satisfying reliability for both social capital and ERICA instruments. Convergent and discriminant validity analyses were as well conducted for both instruments. The Average Variance Extracted (AVE) was between 0.51 and 0.75 for social capital subscales and between 0.50 and 0.70 for ERICA subscales, which is above the 0.50 threshold for convergent validity. The square roots of all AVE indices were calculated for discriminant validity analysis. All results were between 0.71 and 0.87 , which are above the intercorrelations of social capital subscales (see Table 5). As for ERICA, results were between 0.71 and 0.83 , which are above the intercorrelations of its subscales (see Table 5). We concluded to satisfying CR, and to convergent and discriminant validity of our instruments, which allows us to conduct further analyses using those measures.

For practical reasons and better comprehension, we have calculated a single score for social capital, by calculating the general average over all the sub-dimensions. For the rest of the study, SK as a second-order construct will then be considered.

\subsection{Descriptive statistics and variances}

Normality tests showed that all constructs violate normality $(p>0.05$; see Table 3 for Kolmogorov-Smirnov and Shapiro-Wilk's tests results). Hence, all the following statistical analyses will be non-parametrical.

Mann-Whitney $U$ tests indicate significant differences $(p<0.05)$ between gender for three constructs only, with IEC and ITM displaying higher means for Females (respectively $\mathrm{M}_{\mathrm{Females}}=3.21, \mathrm{M}_{\text {Males }}=2.98$; and $\mathrm{M}_{\text {Females }}=2.21, \mathrm{M}_{\text {Males }}=1.83$ ), and CEC a higher mean for Males $\left(\mathrm{M}_{\mathrm{Females}}=1.29, \mathrm{M}_{\text {Males }}=1.66\right)$. 
Table 3 Descriptive results of Erica and SK scales

\begin{tabular}{llllccll}
\hline & $\mathrm{M}$ & $\mathrm{SD}$ & $\mathrm{Md}$ & Skewness & Kurtosis & $\mathrm{D}_{\mathrm{K}-\mathrm{S}}$ & $\mathrm{W}_{\mathrm{S}-\mathrm{W}}$ \\
\hline IAR & 2.41 & 1.08 & 2.40 & 0.402 & 1.490 & $0.071^{*}$ & $0.966^{* *}$ \\
IEC & 3.08 & 0.73 & 3.00 & -0.699 & 0.074 & $0.121^{* *}$ & $0.943^{* *}$ \\
ITM & 1.99 & 1.03 & 2.00 & -0.076 & -0.753 & $0.065^{*}$ & $0.977^{* *}$ \\
CEC & 1.49 & 0.08 & 1.40 & 0.941 & 1.229 & $0.110^{* *}$ & $0.922^{* *}$ \\
IEM & 2.18 & 0.81 & 2.20 & -0.036 & -0.374 & $0.078^{* *}$ & 0.988 \\
CDM & 0.98 & 0.85 & 1.00 & 0.838 & 0.172 & $0.126^{* *}$ & $0.913^{* *}$ \\
SK & 4.45 & 0.08 & 4.50 & -0.158 & -0.558 & $0.080^{* *}$ & $0.983^{*}$ \\
\hline
\end{tabular}

${ }^{*} p<0.05 ;{ }^{* *} p<0.01$

Kruskal-Wallis $H$ tests indicate significant differences $(p<0.01)$ according to professional status for two constructs only, students displaying the highest CEC and CDM means (respectively $\mathrm{M}=2.06$ and $\mathrm{M}=1.27$ ). For education, $H$ tests indicate significant differences $(p<0.05)$ for two constructs only, Bachelors displaying the highest ITM mean $(\mathrm{M}=2.33)$ and High School Graduates (HSG) the highest CEC mean $(\mathrm{M}=2.13)$. For geographical region, $H$ tests $(p<0.05)$ indicate that Central and Western Africa (CWA) displays higher IAR and IEM means (respectively $\mathrm{M}=2.91$ and $\mathrm{M}=2.63$ ), and Caribbean highest ITM, CEC, $\mathrm{CDM}$ and $\mathrm{SK}$ means (respectively $\mathrm{M}=2.57, \mathrm{M}=1.88, \mathrm{M}=1.42$ and $\mathrm{M}=5.38$ ). It appears that it is either CWA or Caribbean countries participants that display the highest means on the constructs, Europe participants scoring systematically the lowest means. CEC appears as the only construct that variates significantly according to each demographic variable. See Table 4 for details.

Spearman $\rho$ intercorrelation table displays significant correlations between all the constructs, except between IEC and: SK, IEM, CEC and CDM. The two CoRL constructs (CDM and CEC) display the highest intercorrelation index: $r_{s}=0.638$, $p<0.01$. These results are in line with Kaplan et al.'s (2017) findings: co-regulation is not related to the exercise of individual control over the environment. Furthermore, IEC is the only regulation latent factor not related to social capital (Table 5).

\subsection{CoRL and SRL as co-predictors of MOOC achievement}

According to many authors (Holmbeck 1997; Jaccard and Wan 1995; Shrout and Bolger 2002), structural equation methods help analyzing the roles of variables by handling measurement errors, multicollinearity and non-linearity issues. They also reduce errors resulting from the non-normality of the distributions and from the nature of the used measurement scales. We used the maximum likelihood method, which is robust when dealing with non-normal distributions (Benson and Fleishman 1994). To verify $\mathrm{H} 1$ and $\mathrm{H} 2$, we positioned MOOC final score as the outcome variable and all the ERICA subscales and social capital as predictors (covariables). CEC, CDM and IEC were the only regulation variables that predicted MOOC final score significantly, our data fitting excellently the model: $\chi^{2} / \mathrm{df}=$ $1.27, p=0.283 ; \mathrm{CFI}=0.99 ; \mathrm{NNFI}=0.98 ; \mathrm{RMSEA}=0.012$. Figure 1 displays the 
Table 4 ERICA and SK scores by gender, professional status, education and geographical region

\begin{tabular}{|c|c|c|c|c|c|c|c|c|c|}
\hline & $\mathrm{N}$ & $\%$ & IAR & IEC & ITM & CEC & IEM & CDM & SK \\
\hline \multicolumn{10}{|l|}{ Gender } \\
\hline $\mathrm{F}$ & 253 & 55.66 & 2.27 & 3.21 & 2.21 & 1.29 & 2.11 & 0.91 & 4.34 \\
\hline M & 201 & 44.33 & 2.53 & 2.98 & 1.83 & 1.66 & 2.25 & 1.04 & 4.55 \\
\hline \multicolumn{10}{|l|}{ Professional status } \\
\hline Business owner & 3 & 0.50 & 1.80 & 3.80 & 2.00 & 0.00 & 3.00 & 0.00 & 1.00 \\
\hline Higher Managerial Professional Occupations & 82 & 17.96 & 2.29 & 3.16 & 1.85 & 1.18 & 1.98 & 0.81 & 4.18 \\
\hline Employee & 48 & 10.67 & 2.38 & 2.86 & 1.92 & 0.96 & 2.25 & 0.87 & 4.43 \\
\hline Intermediary profession & 13 & 2.95 & 1.83 & 3.23 & 2.43 & 0.67 & 2.23 & 0.17 & 4.77 \\
\hline Student & 139 & 30.54 & 2.41 & 2.87 & 1.92 & 2.06 & 2.36 & 1.27 & 4.69 \\
\hline Job seeker & 163 & 35.92 & 2.56 & 3.24 & 2.12 & 1.45 & 2.11 & 0.95 & 4.43 \\
\hline Non-active & 3 & 0.50 & 1.00 & 4.00 & 2.00 & 0.00 & 2.00 & 0.00 & 4.00 \\
\hline \multicolumn{10}{|l|}{ Education } \\
\hline High School Graduation & 13 & 2.91 & 2.07 & 2.87 & 1.00 & 2.13 & 2.50 & 1.00 & 3.90 \\
\hline University 2nd year & 32 & 7.09 & 1.95 & 2.94 & 1.95 & 1.31 & 2.10 & 0.85 & 4.43 \\
\hline Bachelor & 91 & 19.90 & 2.60 & 3.20 & 2.33 & 1.76 & 2.20 & 0.99 & 4.72 \\
\hline Masters & 238 & 52.42 & 2.48 & 3.11 & 2.05 & 1.34 & 2.22 & 1.05 & 4.48 \\
\hline $\mathrm{PhD}$ & 33 & 7.28 & 2.52 & 3.24 & 1.73 & 1.51 & 1.96 & 0.88 & 4.17 \\
\hline \multicolumn{10}{|l|}{ Region } \\
\hline Europe & 286 & 63.10 & 2.20 & 3.50 & 1.20 & 0.70 & 1.30 & 0.10 & 3.44 \\
\hline North Africa & 54 & 11.65 & 2.22 & 3.08 & 1.89 & 1.33 & 2.00 & 0.84 & 4.07 \\
\hline Central \& Western Africa & 99 & 21.84 & 2.91 & 3.06 & 2.08 & 1.84 & 2.63 & 1.23 & 5.18 \\
\hline Caribbean & 15 & 3.40 & 2.58 & 3.04 & 2.57 & 1.88 & 2.43 & 1.42 & 5.38 \\
\hline
\end{tabular}

significant paths: $\mathrm{CEC}(\mathrm{B}=0.300, p<0.05), \mathrm{CDM}(\mathrm{B}=0.197, p<0.05)$ (both CoRL variables), along with IEC $(B=0.156, p<0.01)$ significantly predict MOOC final score $\left(\mathrm{R}^{2}=0.083\right)$, on which $\mathrm{SK}$ has no effect $(\mathrm{B}=0.001$, $p>0.05)$. We accept $H 1$, as co- and self-regulation learning strategies lead to MOOC achievement, but we reject H2, as social capital does not participate to learning as a co-variable of learning regulation.

Table 5 Intercorrelations between SK scale and ERICA subscales

\begin{tabular}{lllllll}
\hline & SK & IAR & IEC & ITM & CEC & IEM \\
\hline IAR & $0.425^{* *}$ & & & & \\
IEC & 0.112 & $0.261^{* *}$ & & & \\
ITM & $0.319^{* *}$ & $0.373^{* *}$ & $0.274 * *$ & & & \\
CEC & $0.425^{* *}$ & $0.364^{* *}$ & -0.039 & $0.174 *$ & $0.357^{* *}$ & $0.359^{* *}$ \\
IEM & $0.367^{* *}$ & $0.572^{* *}$ & 0.107 & $0.329 * *$ & $0.638^{* *}$ & 0.407 \\
CDM & $0.415^{* *}$ & $0.418^{* *}$ & -0.001 & & & \\
\hline
\end{tabular}

${ }^{* *} p<.01 ;{ }^{*} p<.05$ 


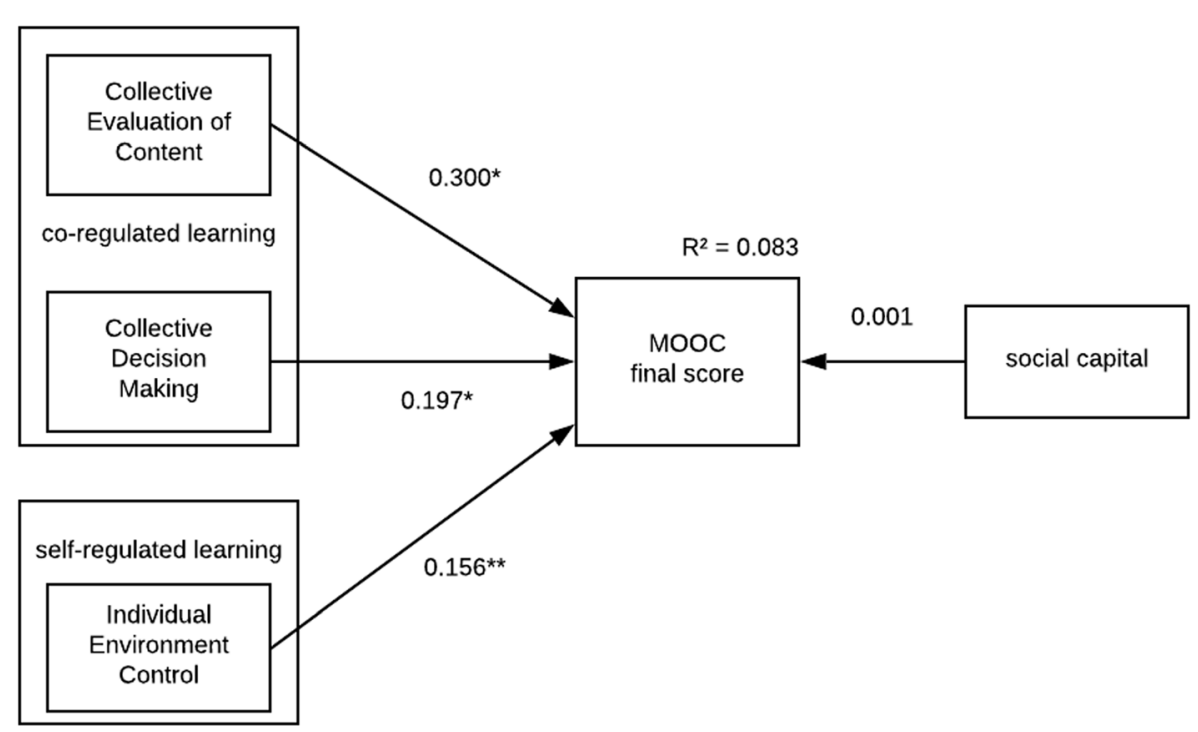

Fig. 1 Model 1: SEM with MOOC achievement predicted by CoRL and SRL but not by SK (H1 and H2)

\subsection{Social capital as a mediator between regulation and learning}

A mediating variable specifies how a predicting variable influences a predicted one. A mediating effect relates to causality. A mediating variable is a process variable that transmits, completely or partially, the impact of an initial independent variable on a dependent variable (MacKinnon et al. 2002). Results show that when SK is positioned as a mediator between regulation strategies and learning, the path between SK and MOOC final score is not significant $(\mathrm{B}=0.404, p>0.05)$. Hence, we reject $H 3$, as social capital doesn't act as a mediator between co- and self-regulated learning and MOOC achievement.

\subsection{Social capital as a moderator of CoRL for MOOC achievement}

A moderating variable affects the relationship between two other variables. It modifies the size, intensity, direction and/or form of the effect of the predictor variable on the predicted variable (Sharma et al. 1981). We used Ping's $(1995,1998)$ method to add social capital moderating effect to Model 1 . After successfully testing Model 1 goodness of it (i.e. 6.3), we standardized all the predictive variables of the model, by subtracting from each value the mean of the variable, to reduce multicollinearity. Then, we calculated the interaction term indicator (the moderating effect of SK) by calculating the product of the sums of the indicators of the predictive variables (CEC, CDM and IEC) and of the moderating variable (SK). We obtained three new variables: CECxSK, CDMxSK and IECxSK. SEM results should verify the goodness of fit between our data and the new model (Model 2) and that the initial predictors in Model 1 do not display significant paths towards MOOC final score anymore. Instead, only the new moderating variable should display significant effects on the predicted variable (as well as other non-moderated variables). The new SEM results show that our data displays satisfying 
fitness with the Model 2: $\chi^{2} / \mathrm{df}=4.91 ; p=0.001 ; \mathrm{CFI}=0.92 ; \mathrm{NNFI}=0.90 ; \mathrm{RMSEA}=$ 0.048 .

Model 2 (Fig. 2) shows that when SK is integrated as a moderating variable, the total variance of MOOC final score increases from $\mathrm{R}^{2}=0.083$ to $\mathrm{R}^{2}=0.390\left(\Delta \mathrm{R}^{2}=0.307\right)$. This demonstrates that the addition of the moderating effect improves the predictive validity of the model (Aiken and West 1991). Indeed, social capital significantly moderates CEC $(\mathrm{B}=0.472, p<0.01)$ and $\mathrm{CDM}(\mathrm{B}=0.484, p<0.05)$, both relating to collective learning regulation strategies. Furthermore, SK doesn't relate to IEC as a moderator, and CEC and CDM do not relate significantly with MOOC final score anymore, demonstrating further validity of Model 2 . We accept H4: social capital is a moderator of learning regulation as a predictor of $M O O C$ achievement. More precisely, social capital only moderates co-regulation strategies for learning (H5). It significantly contributes to the collective evaluation of content, as well as to the collective decision-making process. Conversely, there is no effect of social capital on individual learning regulation strategies such as the individual environment control.

\section{Discussion}

SRL, as a multifaceted construct, does not lead to homogenous effects on outcome variables such as online learning achievement. In our empirical study, collective and individual learning regulation do not contribute to the same extent to MOOC success. Only the co-regulated learning strategies combined with social capital, and the individual environment control acting independently, have significant effects on MOOC

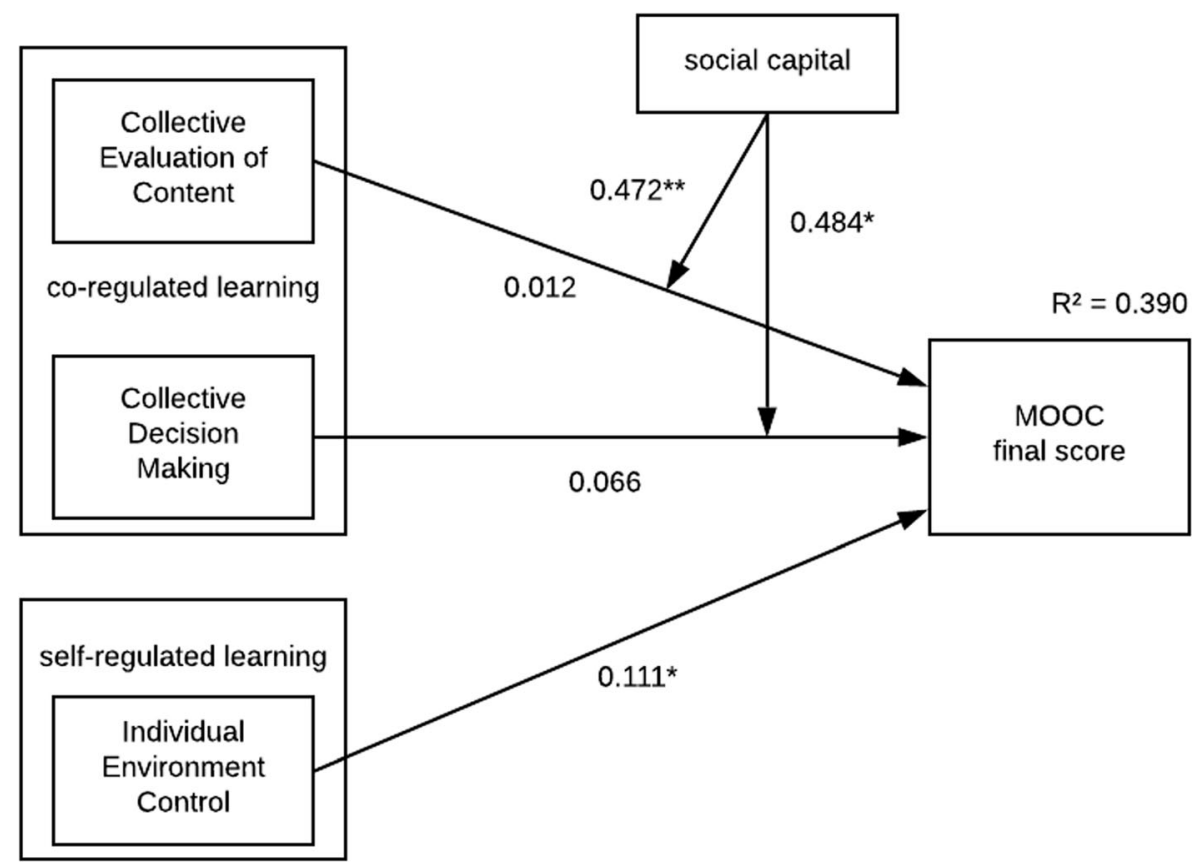

Fig. 2 SEM with MOOC achievement predicted by SRL and SK as a moderator of CoRL (H4) 
final score. The results confirm that the regulated learning phases are not monolithic constructs, and their different phases and dimensions affect differently outcome variables such as online learning.

Our study suggests the existence of social capital as a resource for online regulated learning, separate from collective regulated learning or socially shared regulation of learning (Hadwin et al. 2018. For instance, SSRL has been put in evidence in collaborative learning settings. Social capital as learners' resource in their learning environment and socially shared or co-regulated learning are not to be confused with one another, as collective strategies (collective evaluation of content and decision making) can be specifically moderated by social capital, compared to individual strategies, as shown in our study. Social settings and resources precede the activation of self and co-regulated strategies in a learning context and are to be added to the information the learners and group of learners take into account during the building of their learning process. This being said, it is also possible that co-regulated strategies affect social capital. In other words, during the shared learning process, social capital and co-regulated learning could be interdependent and nurture one another.

Nevertheless, before reaching that stage, social capital needs to be an available resource to begin with, and co-regulated learning could not be activated before first reaching out to other learners. Our main result asks the questions of how online learners seek for peers, and how this process might be dependent on other skills such as digital literacy in social networks and soft skills. There might also be an environment-linked issue, as cultural differences could be determinants or obstacles to peer interactions in online learning or to the constitution of online learning communities.

\section{Conclusion}

This paper shows that social capital has a moderator effect on co-regulated learning. Our study has two major limitations: firstly, the studied sample displayed higher participation that the MOOC registrants' population as they were all active participants at the time they filled in the questionnaire. Our results must then include the fact that they were based on a sample specifically motivated to contribute to the instructional activities. Secondly, the analyses were carried out on only one of the editions of the PM MOOC. However, as the course is proposed on a regular basis, it will be possible to extend and replicate the analyses in subsequent editions. In addition, a more comprehensive and qualitative analysis will be proposed to support the results. As we mentioned earlier, social networks (Twitter and Facebook official PM MOOC accounts) are intensively used during the course session. As a follow-up on our findings, we aim for future research to include the analysis of the use of social networks in the PM MOOC (social media and MOOC forums) as part of the learning process and peer interactions, as from the connectivist theory perspective, they are related to social capital and community of practice building.

Following the global crisis of Covid 19, online learning seems to be the next trend in higher education, with a massive and exponential increase in the quality and the quantity offer. Leading online students to success will certainly be one of the major issues of the coming years, whether in distance education programs, or in an emergency remote teaching situation. As suggested by our study's results, the social dimension in 
online learning can become a lever on which instructional design can rely on, to reach positive learning outcomes. For instance, encouraging interaction about the content, collective problem-solving, forming online learning communities and nurturing the sense of belonging in online learning platforms trough formal and informal interactions, can act as means to enhance learning outcomes, while, at the same time, fostering students' self- and co-regulated strategies for learning. Future studies should assess the moderating impact of specific social interaction tools and platforms (chats, forums, blogs, social networks) on co-regulated learning for academic success.

Availability of data and material Data is available upon request.

Code availability (software application or custom code) Not applicable

\section{Compliance with ethical standards}

Conflicts of interest/competing interests Not applicable.

\section{Appendix}

French adaptation of Chiu et al. (2006) social capital scale (in italic).

Structural capital:

Social interactions.

SIT2. I spend a lot of time interacting with some members in the BlueShop virtual community.

SIT2. Je passe beaucoup de temps à interagir avec d'autres inscrits au MOOC GdP.

SIT3. I know some members in the BlueShop virtual community on a personal level.

SIT3. Je connais quelques inscrits au MOOC GdP à un niveau personnel.

SIT4. I have frequent communication with some members of the BlueShop virtual community.

SIT4. Je communique fréquemment avec quelques inscrits au MOOC GdP.

Relational capital:

Trust.

TR2. Members in the BlueShop virtual community will always keep the promises they make.

TR2. Les inscrits au MOOC GdP tiennent toujours leurs engagements.

TR4. Members in the BlueShop virtual community behave in a consistent manner.

TR4. Les inscrits au MOOC GdP se comportent de manière fiable.

TR5. Members in the BlueShop virtual community are truthful in dealing with one another.

TR5. Les inscrits au MOOC GdP se comportent de manière franche et honnête les uns avec les autres.

Identification.

ID1. I feel a sense of belonging towards the BlueShop virtual community.

ID1. Je ressens un sentiment d'appartenance à la communauté des inscrits au $M O O C G d P$. 
ID2. I have the feeling of togetherness or closeness in the BlueShop virtual community.

ID2. Je ressens un sentiment de solidarité ou de proximité avec les autres inscrits au $M O O C G d P$.

ID3. I have a strong positive feeling toward the BlueShop virtual community.

ID3. Je ressens un fort sentiment positif envers les autres inscrits au MOOC GdP. Cognitive capital:

Shared language.

SL1. The members in the BlueShop virtual community use common terms of jargons.

SL1. Les inscrits au MOOC GdP utilisent un même jargon.

SL2. Members in the BlueShop virtual community use understandable communication pattern during the discussion.

SL2. Les inscrits au MOOC GdP utilisent des manières de communiquer compréhensibles durant les discussions.

SL3. Members in the BlueShop virtual community use understandable narrative forms to post messages or articles.

SL3. Les inscrits au MOOC GdP utilisent des styles de rédaction compréhensibles lorsqu'ils postent ou envoient des messages.

Shared vision.

SV1. Members in the BlueShop virtual community share the vision of helping others solve their professional problems.

SV1. Les inscrits au MOOC GdP partagent les valeurs d'entraide pour la résolution de problèmes.

SV2. Members in the BlueShopvirtual community share the same goal of learning from each other.

SV2. Les inscrits au MOOC GdP partagent le même but d'apprendre les uns des autres.

SV3. Members in the BlueShop virtual community share the same value that helping others is pleasant.

SV3. Les inscrits au MOOC GdP partagent le même sentiment qu'aider les autres est agréable.

\section{References}

Adler, P. S., \& Kwon, S. W. (2002). Social capital: Prospects for a new concept. Academy of management review, 27(1), 17-40. https://doi.org/10.2307/4134367.

Aiken, L. S., \& West, S. G. (1991). Multiple Regression: Testing and Interpreting Interactions. Newbury Park, CA: SAGE Publications.

Artino, A. R. (2007). Self-regulated learning in online education: A review of the empirical literature. International Journal of Instructional Technology and Distance Learning, 4(6), 3-18.

Azevedo, R. (2008). The role of self-regulation in learning about science with hypermedia. In D. Robinson \& G. Schraw (Eds.), recent innovations in educational technology that facilitate student Learning (pp. 127156). Charlotte, NC: Information Age Publishing.

Azevedo, R., \& Jacobson, M. J. (2008). Advances in scaffolding learning with hypertext and hypermedia: A summary and critical analysis. Educational Technology Research and Development, 56(1), 93-100. https://doi.org/10.1007/s11423-007-9064-3. 
Bagozzi, R. P., \& Dholakia, U. M. (2002). Intentional social action in virtual communities. Journal of interactive marketing, 16(2), 2-21. https://doi.org/10.1002/dir.10006.

Bandura, A. (1989). Human Agency in Social Cognitive Theory. American Psychologist, 44(9), 1175-1184. https://doi.org/10.1037/0003-066X.44.9.1175.

Baron, R. M., \& Kenny, D. A. (1986). The moderator-mediator variable distinction in social psychological research: Conceptual, strategic, and statistical considerations. Journal of personality and social psychology, 51(6), 1173. https://doi.org/10.1037/0022-3514.51.6.1173.

Benson, J., \& Fleishman, J. A. (1994). The robustness of maximum likelihood and distribution-free estimators to non-normality in confirmatory factor analysis. Quality and Quantity, 28(2), 117-136. https://doi. org/10.1007/BF01102757.

Bentler, P. M. (1992). On the fit of models to covariances and methodology to the Bulletin. Psychological Bulletin, 112(3), 400-404.

Blau, P. (1964). Power and exchange in social life. Wiley. 352 p.

Boekaerts, M., Pintrich P, R. \& Zeidner, M. (2000). Handbook of Self-Regulation. A Diego, CA: Academic Press.

Borkowski, J. G. (1992). Metacognitive theory: A framework for teaching literacy, writing, and math skills. Journal of learning disabilities, 25(4), 253-257. https://doi.org/10.1177/002221949202500406.

Bourdieu, P. (1986). L'illusion biographique. Actes de la recherche en sciences sociales, 62(1), 69-72. https://doi.org/10.3406/arss.1986.2317.

Bozkurt, A., \& Keefer, J. (2018). Participatory learning culture and community formation in connectivist MOOCs. Interactive Learning Environments, 26(6), 776-788. https://doi.org/10.1080 /10494820.2017.1412988.

Broadbent, J., \& Poon, W. L. (2015). Self-regulated learning strategies \& academic achievement in online higher education learning environments: A systematic review. The Internet and Higher Education, 27, 113. https://doi.org/10.1016/j.iheduc.2015.04.007.

Chae, C., Suh, B., Han, S. H., Han, H., \& Lim, D. H. (2018). Enhancing learner-driven informal learning in a virtual practice community: The Massive Open Online Course (MOOC) as a learning solution for professional development. In Handbook of research on digital content, mobile learning, and technology integration models in Teacher Education (pp. 207-226). IGI Global. https://doi.org/10.4018/978-1-5225-2953-8.CH011.

Chen, Y. H., \& Chen, P. J. (2015). MOOC study group: Facilitation strategies, influential factors, and student perceived gains. Computers \& Education, 86, 55-70. https://doi.org/10.1016/j.compedu.2015.03.008.

Chiu, C. M., Hsu, M. H., \& Wang, E. T. (2006). Understanding knowledge sharing in virtual communities: An integration of social capital and social cognitive theories. Decision support systems, 42(3), 1872-1888. https://doi.org/10.1016/j.dss.2006.04.001.

Cho, M., \& Shen, D. (2013). Self-regulation in online learning. Distance Education, 34(3), $290-301$. https://doi.org/10.1080/01587919.2013.835770.

Coleman, J, S. (1990). Foundations of social capital. Cambridge: Belknap.

Davis, D., Chen, G., van der Zee, T., Hauff, C., \& Houben, G. J. (2016). Retrieval practice and study planning in MOOCs: Exploring classroom-based self-regulated learning strategies at scale. In K. Verbert, M. Sharples, \& T. Klobučar (Eds.), Adaptive and adaptable learning (pp. 57-71). Cham: Springer. https://doi.org/10.1007/978-3-319-45153-4_5.

De Waard, I., Koutropoulos, A., Keskin, N., Abajian, S C., Hogue, R., Rodriguez, C O., \& Gallagher, M S. (2011, October). Exploring the MOOC format as a pedagogical approach for mLearning. In Proceedings of 10th World Conference on Mobile and Contextual Learning (pp. 138-145). https://pdfs. semanticscholar.org/5317/3406caa20421c35cee0abeee6148e63de1bc.pdf

Gasevic, D., Kovanovic, V., Joksimovic, S., \& Siemens, G. (2014). Where is research on massive open online courses headed? A data analysis of the MOOC Research Initiative. The International Review of Research in Open and Distributed Learning, 15(5), 134-176. https://doi.org/10.19173/irrodl.v15i5.1954.

Gillani, N., \& Eynon, R. (2014). Communication patterns in massively open online courses. The Internet and Higher Education, 23, 18-26. https://doi.org/10.1016/j.iheduc.2014.05.004.

Graham, S., Harris, K. R., \& Reid, R. (1992). Developing self-regulated learners. Focus on Exceptional Children, 24(6) https://www.jstor.org/stable/1477462.

Hadwin, A., Järvelä, S., \& Miller, M. (2018). Self-regulation, co-regulation, and shared regulation in collaborative learning environments. In D. H. Schunk \& J. A. Greene (Eds.), Educational psychology handbook series. Handbook of self-regulation of learning and performance (pp. 83-106). Routledge: Taylor \& Francis Group.

Hadwin, A. F., Järvelä, S., \& Miller, M. (2011). Self-regulated, co-regulated, and socially shared regulation of learning. Handbook of self-regulation of learning and performance, 30, 65-84.

Hakkarainen, K., Lipponen, L., \& Järvelä, S. (2002). Epistemology of inquiry and computer-supported collaborative learning. Cscl, 2, 129-156. 
Holmbeck, G. N. (1997). Toward Terminological, Conceptual and Statistical Clarity in the Study of Mediators and Moderators. Journal of Consulting and Clinical Psychology, 65(4), 599-610. https://doi.org/10.1037 /0022-006x.65.4.599.

Hsu, J, Y., Chen, C, C., \& Ting, P, F. (2018). Understanding MOOC continuance: An empirical examination of social support theory. Interactive Learning Environments, 1-19. https://doi.org/10.1080 $/ 10494820.2018 .1446990$

Hu, L. T., \& Bentler, P. M. (1999). Cutoff criteria for fit indexes in covariance structure analysis: Conventional criteria versus new alternatives. Structural equation modeling: a multidisciplinary journal, 6(1), 1-55. https://doi.org/10.1080/10705519909540118.

Hughes, T. A., \& Kritsonis, W. A. (2007). Professional learning communities and the positive effects on student achievement: A national agenda for school improvement. The Lamar University Electronic Journal of Student Research, 4, 1-5.

Jaccard, J., \& Wan, C. K. (1995). Measurement Error in the Analysis of Interaction Effects Between Continuous Predictors Using Multiple Regression: Multiple Indicator and Structural Equation Approaches. Psychological Bulletin, 117(2), 348-357. https://doi.org/10.1037/0033-2909.117.2.348.

Jiang, J. Y., \& Liu, C-W. (2015). High performance work systems and organizational effectiveness: The mediating role of social capital. Human Resource Management Review, 25(1), 126-137.

Johnson, G, B. (2013). Student perceptions of the flipped classroom (Doctoral dissertation, University of British Columbia).

Jones, M. H., Estell, D. B., \& Alexander, J. M. (2008). Friends, classmates, and self-regulated learning: Discussions with peers inside and outside the classroom. Metacognition and Learning, 3(1), 1-15.

Jones, K. M., Stephens, M., Branch-Mueller, J., \& de Groot, J. (2016). Community of practice or affinity space: A case study of a professional development MOOC. Education for Information, 32(1), 101-119.

Jöreskog, K. G., Yang, F., Marcoulides, G., \& Schumacker, R. (1996). Nonlinear structural equation models: The Kenny-Judd model with interaction effects. Advanced structural equation modeling: Issues and techniques, 3, 57-88. https://doi.org/10.1023/A:1014976022227.

Kaplan, J. (2014). Co-regulation in technology enhanced learning environments. In L. Uden, F. J. Sinclair, Y.H. Tao, \& D. LiberonaF (Eds.), Learning Technology for Education in Cloud. MOOC and Big Data, CCIS (446) (pp. 72-81). Springer International Publishing. https://doi.org/10.1007/978-3-319-10671-7_7.

Kaplan, J., de Montalembert, M., Laurent, P., \& Fenouillet, F. (2017). ERICA-an instrument to measure individual and collective regulation of learning. Revue Européenne de Psychologie Appliquée/European Review of Applied Psychology, 67(2), 79-89. https://doi.org/10.1016/j.erap.2017.01.001.

Kellogg, S., Booth, S., \& Oliver, K. (2014). A social network perspective on peer supported learning in MOOCs for educators. International Review of Research in Open and Distributed Learning, 15(5), 263289. https://doi.org/10.19173/irrodl.v15i5.1852.

Kizilcec, R. F., Pérez-Sanagustín, M., \& Maldonado, J. J. (2017). Self-regulated learning strategies predict learner behavior and goal attainment in Massive Open Online Courses. Computers \& Education, 104, 18 33. https://doi.org/10.1016/j.compedu.2016.10.001.

Lee, D., Watson, S, L., \& Watson, W, R. (2019). Systematic literature review on self-regulated learning in massive open online courses. Australasian Journal of Educational Technology, 35(1). https://doi. org/10.14742/ajet.3749

Lin, T, C., Hsu, J, S, C., Cheng, H, L., \& Chiu, C, M. (2012). Exploring individuals' loyalty to online support groups from the perspective of social support. The 16th pacific Asia conference on information system, Ho chi Minh, Vietnam.

Littlejohn, A., Hood, N., Milligan, C., \& Mustain, P. (2016). Learning in MOOCs: Motivations and selfregulated learning in MOOCs. The Internet and Higher Education, 29, 40-48. https://doi. org/10.1016/j.iheduc.2015.12.003.

Liu, S. H. (2012). A multivariate model of factors influencing technology use by preservice teachers during practice teaching. Journal of Educational Technology \& Society, 15(4), 137-149. https://doi.org/10.1016 j.iheduc.2015.12.003.

MacKinnon, D. P., Lockwood, C. M., Hoffman, J. M., West, S. G., \& Sheets, V. (2002). A Comparison of Methods to Test Mediation and Other Intervening Variable Effects. Psychological Methods, 7(1), 83-104. https://doi.org/10.1037/1082-989x.7.1.83.

Magen-Nagar, N., \& Cohen, L. (2016). Learning strategies as a mediator for motivation and a sense of achievement among students who study in MOOCs. Education and Information Technologies, 1-20. https://doi.org/10.1007/s10639-016-9492-y

Milligan, C., Littlejohn, A., \& Margaryan, A. (2013). Patterns of engagement in connectivist MOOCs. Journal of Online Learning and Teaching, 9(2), 149-159 https://jolt.merlot.org/vol9no2/milligan_0613.pdf. 
Nahapiet, J., \& Ghoshal, S. (1998). Social capital, intellectual capital, and the organizational advantage. Academy of management review, 23(2), 242-266. https://doi.org/10.5465/amr.1998.533225.

Oztok, M., Zingaro, D., Makos, A., Brett, C., \& Hewitt, J. (2015). Capitalizing on social presence: The relationship between social capital and social presence. The Internet and Higher Education, 26, 19-24. https://doi.org/10.1016/j.iheduc.2015.04.002.

Perry, J. C., Fisher, A. L., Caemmerer, J. M., Keith, T. Z., \& Poklar, A. E. (2018). The role of social support and coping skills in promoting self-regulated learning among urban youth. Youth \& Society, 50(4), 551570. https://doi.org/10.1177/0044118X15618313.

Ping, R. (1995). A Parsimonious Estimating Technique for Interaction and Quadratic Latent Variables. The Journal of Marketing Research, 32, 336-347. https://doi.org/10.2307/3151985.

Ping, R. (1998). EQS and LISREL Examples Using Survey Data. In R. E. Schumacker \& G. A. Marcoulides (Eds.), Interaction and Nonlinear Effects in Structural Equation Modeling (pp. 63-100). London: Lawrence Erlbaum Associates.

Pintrich, P. R. (2000). The role of goal orientation in self-regulated learning. In M. Boekaerts, P. R. Pintrich, \& M. Zeinder (Eds.), Handbook of self-regulation (pp. 451-502). San Diego, CA: Academic Press.

Pintrich, P. R., Smith, D. A., Garcia, T., \& McKeachie, W. J. (1993). Reliability and predictive validity of the Motivated Strategies for Learning Questionnaire (MSLQ). Educational and psychological measurement, 53(3), 801-813. https://doi.org/10.1177/0013164493053003024.

Putnam, R. (1993). The prosperous community: Social capital and public life. The American Prospect, 13(Spring), Vol. 4.

Sarirete, A., \& Brahimi, T. (2014, November). Enabling communities of practice within MOOCs. In 2014 International Conference on Web and Open Access to Learning (ICWOAL) (pp. 1-4). IEEE. https://doi. org/10.1109/ICWOAL.2014.7009232

Schunk, D. H., \& Zimmerman, B. J. (1998). Self-regulated learning, from teaching to self-reflective practice. New York: The Guilford Press.

Schumacker, R. E., \& Lomax, R. G. (1996). A beginner's guide to structural equation modeling. New Jersey: Lawrence Erlbaum Associates, Inc.

Sharma, S., Durand, R. M., \& Gur-Arie, O. (1981). Identification and Analysis of Moderator Variables. Journal of Marketing research, 18, 291-300. https://doi.org/10.2307/3150970.

Shrout, P. E., \& Bolger, N. (2002). Mediation in Experimental and Nonexperimental Studies: New Procedures and Recommendations. Psychological Methods, 7(4), 422-445. https://doi.org/10.1037/1082-989X.7.4.422.

Siemens, G. (2005). Connectivism: A learning theory for the digital age. International Journal of Instructional Technology and Distance Learning, 2(1).

Siemens, G., Downes S., Cormier, D., \& Kop, R. (2010). PLENK2010 -Personal Learning Environments, Networks and Knowledge. Course blog http://connect.downes.ca

Struminger, B., Arora, S., Zalud-Cerrato, S., Lowrance, D., \& Ellerbrock, T. (2017). Building virtual communities of practice for health. The Lancet, 390(10095), 632-634. https://doi.org/10.1016/S01406736(17)31666-5.

Tantardini, M., \& Kroll, A. (2015). The role of organizational social capital in performance management. Public Performance \& Management Review, 39(1), 83-99. https://doi.org/10.1080 /15309576.2016.1071163.

Terras, M. M., \& Ramsay, J. (2015). Massive open online courses (MOOCs): Insights and challenges from a psychological perspective. British Journal of Educational Technology, 46(3), 472-487. https://oi. org/10.1111/bjet.12274.

Tsai, W., \& Ghoshal, S. (1998). Social capital and value creation: The role of intrafirm networks. Academy of management Journal, 41(4), 464-476. https://doi.org/10.2307/257085.

Tschofen, C., \& Mackness, J. (2012). Connectivism and dimensions of individual experience. The International Review of Research in Open and Distributed Learning, 13(1), 124-143. https://doi. org/10.19173/irrodl.v13i1.1143.

Wenger, E., McDermott, R, A., \& Snyder, W. (2002). Cultivating communities of practice: A guide to managing knowledge. Harvard Business Press.

Winne, P. H., \& Hadwin, A. F. (2008). The weave of motivation and self-regulated learning. In D. H. Schunk \& B. J. Zimmerman (Eds.), Motivation and self-regulated learning: Theory, research, and applications (p. 297-314). Lawrence Erlbaum Associates Publishers.

Young, A., \& Fry, J. D. (2008). Metacognitive awareness and academic achievement in college students. Journal of the Scholarship of Teaching and Learning, 8(2), 1-10. https://doi.org/10.4236 /psych.2017.812125. 
Zimmerman, B. J. (1998). Developing self-fulfilling cycles of academic regulation: An analysis of exemplary instructional models. In D. S. E. B. J. Zimmermann (Ed.), Self-Regulated learning: From teaching to selfreflective practice (pp. 1-199). New York, London: The Guilford Press.

Zimmerman, B. J. (2001). Becoming a Self-Regulated Learner: An Overview. Theory into Practice, 41(2), 64-70. https://doi.org/10.1207/s15430421tip4102_2.

Publisher's note Springer Nature remains neutral with regard to jurisdictional claims in published maps and institutional affiliations. 